\title{
Reducing post-harvest losses in fruits and vegetables for ensuring food security - Case of Sri Lanka
}

\begin{abstract}
In Sri Lanka, $70 \%$ of 21 million population live in non-urban areas, and agriculture provides livelihood for approximately $40 \%$ of them. The agricultural marketing process in the country is a complex operation due to services and functions involved in moving a crop product from where it was produced to where it would finally be consumed. Further, with a wide range of agricultural crops being produced, post-harvest handling process create different degrees of quantitative and qualitative losses in a complex market chain, which are estimated at $20 \%$ to $40 \%$ for vegetables and $30 \%-40 \%$ for fruits. Improper and non-scientific post-harvest practices and handling, gaps in integration of cold chain practices \& elements with post-harvest process, and lack of knowledge \& awareness on many related aspects at grass root farmer level etc. appear to contribute to losses that finally prevent due economic benefits reaching the small-scale producer. In order to increase the effectiveness of post-harvest process handling of fruit and vegetables, appropriate corrective measures targeting small scale producers as well as commercial scale producers need to be popularized and practiced. At small scale producer level, promotion of appropriate low-cost post-harvest practices and procedures, facilitating low-cost cold chain elements and user-friendly information flow mechanism on market situation would certainly help avoid some of the steps that lead to losses. Monitoring system of commercial post-harvest handling process that ensure scientific bulk handling, storage and transportation of fruit and vegetables, properly designed economic centers with well regulated environmentcontrolled storages etc. would greatly reduce loses in bulk handling, ensuring better food security in the island.
\end{abstract}

Keywords: Fruits, Vegetable, Cold Chain, Cold Storage, Technologies, Food Security

\author{
Volume 9 Issue I - 202 I \\ Leelananda Rajapaksha, ${ }^{1,2}$ DMC Champathi \\ Gunathilake,' SM Pathirana,' TN Fernando' \\ 'National Engineering Research and Development Centre, Sri \\ Lanka \\ ${ }^{2}$ Faculty of Engineering, University of Peradeniya, Sri Lanka
}

Correspondence: DMC Champathi Gunathilake, National Engineering Research and Development Centre, Ekala, Ja-Ela, Sri Lanka, Tel +947 I774I I05, ORCID 0000-0003-1 205-8042, Email champathi@hotmail.com

Received: January 15, 2021 | Published: February 02, 2021

\section{Introduction}

The Sri Lankan economy is primarily based on agriculture. More than 70 percent of the population living in rural areas of the country dependent on agriculture as the major source of livelihood. Currently, the sector contributes 7.9\% of the country's Gross Domestic Production (GDP) and employees more than $31.2 \%$ of the total population. ${ }^{1}$ Sri Lanka is a tropical island with 46 different agro-ecological regions and two monsoons or major rain fall periods. This enables the production of a range of durable and perishable crops. However, crop production is often seasonal and dependent on availability of water. This also result in gluts soon after harvest followed by scarcities and high market prices during off seasons.

The annual loss of fruits during postharvest operation represent about 210,000 metric tons of fruits, which is about $30 \%-40 \%$ of the harvest, representing approximately US\$ 90 million losses in financial terms. $^{2}$ Annual loss of vegetables during post-harvest operations is quantified about 370,000 metric tons, which is about $20 \%-40 \%$ of the total harvest. This represent approximately US\$ 110 million.

As a tropical island, relatively warm temperature and high relative humidity (RH) exist throughout the year in Sri Lanka. Exposure of perishable fresh produces such as fruits and vegetables to high temperature and $\mathrm{RH}$ just after harvesting is highly unfavorable and lead to initiation of rapid deterioration. In order to reduce post-harvest losses of produce, it is very much required to provide temperature
\& humidity-controlled storage systems, which control the rate of deterioration of fresh produce. This certainly extends shelf-life of fresh fruits and vegetables within possible limits but it's also decided by other post-harvest operation such as incorrect harvesting before reaching correct maturity, improper handling procedures in the field, improper packaging at various stages of the process, and improper transportation and incorrect retail selling approaches are some of the major reasons for such high post-harvest losses. Total post-harvest damage due to above mentioned reasons are cumulative and finally affect the quality and durability. Further, storage life of fruits and vegetables could be extended greatly by removing the field heat just after harvesting. Suitable field operated or convenient cooling systems are needed to remove field heat from fresh produce before going to storage.

In general, temperature and humidity play major role in reducing post-harvest losses of fruits and vegetables during most part of the post-harvest channel. Temperature is the single most decisive factor affecting the deterioration rate of freshly harvested commodities. Low temperature and proper relative humidity are required to be maintained in order to reduce metabolic reactions, weight loss and freshness of fruits and vegetable. During storage, low temperature reduces microbial activities too. ${ }^{3}$ Previous research studies have shown that prost-harvest practices such as harvesting at correct maturity, careful handling, proper transportation are very important before storing in cold storage in order to reduce post-harvest losses of fruits and vegetables. ${ }^{4-7}$ 
At present, there are lack of studies available for investigate fruits and vegetable post-harvest losses and technology gaps in Sri Lanka. Therefore, objective of this review is to investigate causes for postharvest losses of fruits and vegetables, and present status of fruits and vegetable supply chain in Sri Lanka; from farmer level to up to consumer. In addition, this work aims at identifying technology gaps, successful closing of which would help reduce post-harvest losses of fruits and vegetables in Sri Lanka.

\section{Status quo - post harvest practices, market operations and losses}

Sri Lanka is divided into three (3) major agro-climatic zones i.e. dry zone, intermediate zone and wet zone based on the received rainfall during 2 major monsoons. These 3 major zones are subdivided into 46 different agro-ecological regions based on altitude and rainfall. Figure 1 shows the agro-ecological zones of Sri Lanka. A verity of vegetables and fruits are grown in these 46 different agroecological zones. Different types of vegetables are grown in different type agro-ecological zones throughout the country and large numbers of subsistence farmers are involved in small scale traditional fruits and vegetable cultivation. Vegetable cultivation can be broadly classified into low country vegetables (mostly tropical vegetables) and upcountry vegetables (mostly temperate vegetables). Presently, commercial cultivation of vegetables with substantial capital investment is becoming popular as well. According to the available statistics, in 2018 , the overall vegetable production was 705,000 metric tons and extent of cultivation was 61,000 ha. ${ }^{8}$

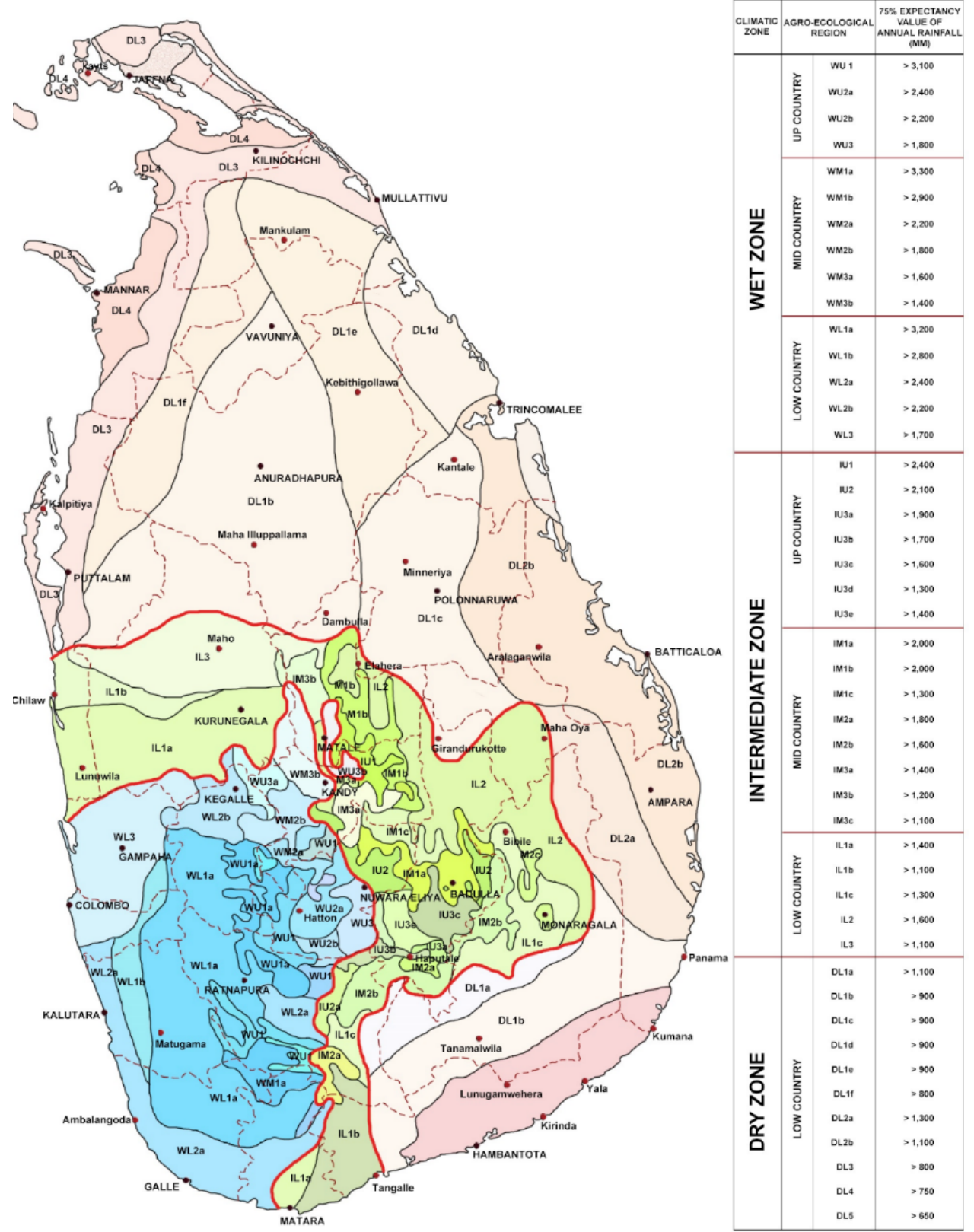

Figure I Agro-ecological zones of Sri Lanka. ${ }^{52}$ 
Low country vegetables are generally cultivated under rain-fed conditions in mostly dry and intermediate zones on small plots of land or in-home gardens using little input by way of fertilizer and/or pesticides, except in paddy fields during the dry season under irrigated conditions. Common low country vegetables are eggplant, okra, pumpkin, tomato, bitter gourd, snake gourd, long beans, onion, leafy vegetables, luffa, drumstick, capsicum, etc. Harvesting of low country vegetables is done on seasonal basis. Upcountry vegetables are leeks, beans, cabbage, beetroot, carrot, potato etc., cultivated in upcountry wet zone more intensively under rain-fed or irrigated conditions at high altitudes. The cultivation is staggered and harvesting is generally carried out throughout the year.

The main fruits grown in Sri Lanka are mango, papaya, pineapple, avocado, banana, watermelon, rambutan, mangosteen, wood apple, guava, pomegranate and jackfruits. Banana, pineapple and papaya are cultivated commercial-scale whereas, other fruit varieties such as mango, wood apple, guava, pomegranate, avocado, etc. are supplied mainly from home gardens. Moreover, a considerable proportion of the supply of banana, and papaya is coming from home gardens as well. Further, considerable amount of tropical grapes and oranges are cultivated in Sri Lanka. However, the local demands for certain temperate fruits such as apples, oranges, grapes and dates are met through imports.

Most fruits are generally cultivated under rain-fed conditions. Pineapples are mostly cultivated in Gampaha and Kurunegala districts in coconut lands as an inter-crop. Except for banana, pineapple and papaya, all other fruits are highly seasonal therefore, during glut periods large quantities are wasted. The present average extent under fruit crops is about 69,800 ha. Average annual production is about 590,000 metric tons, of which about $50-55 \%$ is locally consumed, 30 $40 \%$ is wasted and about $11 \%$ is being exported in $2018 .{ }^{8}$

\section{Fresh chain market operations - Sri Lanka}

The fruits and vegetables fresh chain in Sri Lanka is somewhat complex process with a series of services and functions involved in moving a product or commodity from where it produced to where it would finally be consumed. ${ }^{9-11}$ A change was observed in post-harvest channel of fruits and vegetables after recent establishment of regional wholesale markets centers known as Dedicated Economic Centers in few strategic locations in the island, such as Tambuttegama, Vaunia, Veyangoda, Welisra, Meegoda, Narahenpita and Embilipitiya. In addition, Dambulla Dedicated Economic Centre and Manin Market at Colombo function as central wholesale markets.

At present, a major portion of fruits and vegetables is brought through the regional wholesale markets centers to central whole sale markets from producing areas. From there the commodities are directly supplied for retail selling. Figure 2 shows the different types of postharvest marketing channels used to move fruits and vegetables from the producer to the consumer. Though different marketing channels available for producers, all the channels may not be available for all the producers. Very recently, several efficient marketing channels have been established directly between the farmers/producers and the supermarket network without going through either the collector or the whole seller. Further, some supermarket networks have established their own collecting centers in major vegetable producing areas with improved handling, packaging and transportation integrating elements of cold chain as appropriate. ${ }^{9}$

As in the case of many other developing countries, a major part of the fruits and vegetables in Sri Lanka is produced in smallholdings and home gardens and are usually intended for domestic market. Theses commodities, before reaching the consumer, pass through post-harvest channel similar to that shown in Figure 2. Due to use of improper post-production practices serious quantitative and qualitative losses occur in all steps of fruits and vegetables marketing channel, which could amount to $30-40 \%$ of the total production, with approximate loss of LKR 13 billion i.e. approx. US\$ 72.2 million. $^{2}$

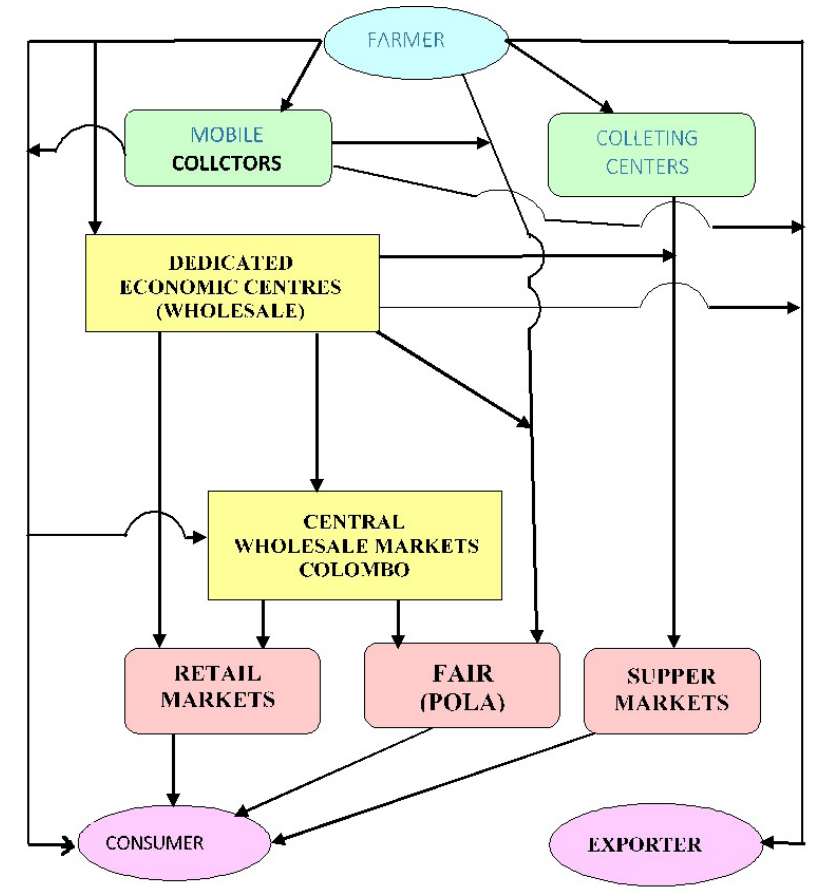

Figure 2 Vegetable and fruit fresh (marketing) channels., ${ }^{9,27}$

\section{Harvesting and associated operations}

Fruits and vegetables are often harvested either at an immature stage or at an advance stage of maturity. Immaturely harvested fruits do not ripen naturally and even if they did, the quality characteristics are extremely poor. When fruits are harvested pass (or later than) the correct maturity stage, inherent physiological developments render them more susceptible to injury and damages when handling at the time of harvest and subsequently during sorting, grading and transportation as well. It is a common practice for the majority of vegetables to be harvested at an over-mature stage, yet, the postharvest losses become significant then, for example, the post-harvest losses in okra, beans, long beans and bitter gourd are extremely high due to toughening of texture when harvested at over-maturity., ${ }^{910}$

\section{Sorting, grading and pre-treatments}

At present sorting and grading are carried out manually to some extent by wholesale and retail traders especially at the super market level. Most small-scale Sri Lankan farmers market their produce without sorting and grading. No mechanical grading and sorting facilities are generally used or available in commercial scale. Vegetables such as leeks, carrots, radish and beetroot are usually washed after harvesting to remove all sands and stones, soil clods and plant debris. For this purpose, some farmers may even use polluted water available in streams and rivers which may result in contaminating the vegetables with bacteria and pesticide residues. Latex secretion causes many problems in the fruit industry, reducing the quality. Therefore, pre-treatments and washing are required after harvesting but it is not generally practiced. ${ }^{9}$ 


\section{Handling and transportation}

A major part of the losses occurs during transportation from farm gate to collection centers, and then to a village fair or wholesale market, and subsequently retail outlets. Because of the high transportation cost involved (in comparison with the quantity to be transported), the collector or whole seller generally tends to transport the maximum amount possible. ${ }^{6,9,10}$ During transportation, it is a common practice that the people are sitting and sleeping on the poly-sacks in which fruits and vegetables are tightly packed. In addition, rough handling loading and unloading take place during transportation, causing serious damages to tender fresh produce. Further, in remote areas, due to lack of information on local market situation, harvesting time of vegetable may not fully tally with the market demand situation, resulting the packed vegetables to stay in the vehicle two or even three days before unloading, damaging a significant portion of the produce. ${ }^{6,9}$

Rough handling causes mechanical damages, where poor packaging and distribution aggravate the problem. Currently, vegetables are often tightly forced packed into polypropylene sacks. These sacks do not provide sufficient ventilation and result in temperature build up within the heap, accelerating both toughening and senescence. In usual practice, fruits and vegetables packed in few poly-sacks are kept near roadside until the collectors pick them up, exposing the fresh produce to whether; sun or rain. Types of packaging used by traders do not accommodate or compensate for possible damages due to uneven road conditions, high ambient temperature and humidity conditions that prevail during the extended period of transportation; all of which accelerate the deterioration of quality. The degree of damage accumulates as the time spent in the vehicle prolongs. Thus, produce is often bruised, infested by post-harvest pathogens and is not in the optimum quality when reaching distribution points. ${ }^{12,13}$

Scientific storage: Sri Lanka is a tropical island, where temperature and humidity levels of the environment are relatively higher Perishable fresh produce such as fruits and vegetables start deteriorate rapidly just after harvesting due to this generally warm humid environment. However, the storage life of fruits and vegetables can be extended greatly by removing the field heat and applying cooling after harvesting as soon as possible. As stated earlier, temperature and humidity play a major role in the process of post-harvest losses of fruits and vegetables. In fact, temperature is the single most important factor affecting the deterioration rate of freshly harvested commodities. Proper relative humidity (RH) is required to be maintained to reduce weight loss and freshness during storage. ${ }^{3}$ However, at present, temperature \& humidity-controlled storages facilities of sufficiently large scale are not available as a service. This situation leads to waste of harvest when there is a surplus of local supplies, where remaining fruits and vegetables are just disposed as garbage by farmers, collector, whole sellers and retailers. Therefore, large heaps of waste fruits and vegetable could be observed seasonally near wholesale markets etc. This points to the need for handling postharvest process in a systematic and scientific manner, by managing supply and demand, suitably holding the surplus where necessary, to avoid loss of harvest. ${ }^{14}$

\section{Factors and inadequacies attributing to losses}

Seasonality of crops and pre-harvest practices: The production of most fruits and vegetables are seasonal and during harvesting periods a glut in production exits. Hence the prices of these commodities tend to slump to very low levels that are disadvantages to farmers. On the other hand, during the off-season the production is low and the prices increases as demand increase. This situation drastically affects operation of of an efficient marketing system, especially the export market, due to price fluctuation and non-uniformity of the supply volumes of fruits and vegetables throughout the year. Farmers often practice improper pre-harvest practices such as the use of lower quality planting material \& seeds, application of excess quantities of pesticides, use of pesticides that are not recommended by the authorized institutions, and not adhering to pre-harvest interval requirement and good practices recommended by relevant authorities. These factors very seriously affect the quality and food-safety aspects of fruits and vegetables produced. ${ }^{9}$

Inadequacies in the process: In the local context, poverty of the farming community and lack of capital to acquire improved technologies, for example by producers, collectors, wholesale and retail traders, is one of the serious constraints for reducing pot harvest losses. For example, fresh fruits and vegetables are packed mainly in poly-sacks for transportation and this practice leads to serious quantitative and qualitative losses, amounting to estimated $20 \%$ loss during handling and transportation alone. ${ }^{9,10}$ Whereas recent research has shown that the use of plastic crates for handling and transportation of fruits and vegetables reduces the losses occurring in the market chain from $30 \%$ to $5 \%$ and the quality and safety of fruits and vegetables reaching the consumer is appreciably improved (IPHT). However, the usage of this simple approach for fruits and vegetables is very low due to involved additional cost. Even though the Government has established several wholesale marketing centers in various part of the country dedicated for efficient handling of fresh produce, the whole of the premises and the surrounding, in most of the cases, have not been properly designed to scientifically handle fruits and vegetables in the post-harvest stages. For example, trucks and lorries loaded with produce just wait in the sun and whether until they are unloaded, space provided for a wholesale trader is not adequate to stack plastic crates etc., for example space planning and sheltered parking for loaded vehicles are just two aspects should receive realistic attention. ${ }^{9}$

Lack of adequate marketing and awareness channels that link the fruits and vegetable producers in major growing areas with the urban supermarket network and exporters, where the demand for quality produce exits, is another issue relating to improving marketing. Due to nature of trading, the farmers are reluctant to offer high-quality produce to the common market because the available system of marketing of fruits and vegetable is such that, regardless of handling method and resultant quality, the same prices are paid. ${ }^{9,10}$

Inadequacy of trained manpower in this area of specialization and deficiencies in the agricultural extension service has affected the improvement of marketing channels of fruits and vegetables. ${ }^{9}$ Since this sector include a large number of farmers, collectors, wholesale and retail traders there is serious requirement to strengthen the extension mechanism of existing public and private institutions, perhaps by utilizing communication systems (such as communication apps) that relevant data and information reach large number of personnel involved in the marketing chain more effectively. ${ }^{9-11}$

Testing and certification and market intelligence/information systems: Many countries enforce strict food-safety and quality standards on imported food items. On the other hand, the local exporters have to conduct and comply with various inspection, testing and certification of their export commodities to suit the recipients/ overseas regulations and procedures of foreign clients. However, most of these services and requirements are not practiced/readily available within Sri Lanka. As a result, the exporters are forced to depend on more expensive foreign sources for these basic services. ${ }^{9}$ For example, 
the cost of analysis for pesticides residues, when outsourced from another country, is prohibitive, which in most of the cases are out of reach of common trader or even the exporter.

Farmer is distanced from his market, physically as well as in communication, and therefore does not have adequate up to date information and awareness on dynamics on market requirement, demand, prices and situation etc. At present, there is no proper market information sharing system, that is user friendly, and that could reach the small-scale producer and farmer level. Therefore, farmers depend on the price information provided by the trader or the collector, in some cases this may be the driver of the vehicle, which could be inaccurate and outdated in the context of market completion and time frame..$^{9,11}$

\section{Fresh chain practices and post-harvest losses}

\section{Correct practices}

Figure 3 shows steps of food/cold chain practices of fruits and vegetable that are accepted to be correct in research, where, the operations and steps lead to reduce post-harvest loess of the fruits and vegetables produce chain. However, depending on the type of produce, some cold chain steps/operations may not be essential. Yet careful handling of the produce, suitably control of temperature and humidity in storages are an essential part of the process to minimize losses. ${ }^{3-6,15,16}$ Some of the steps in the Fig 3 are discussed in subsequent sections

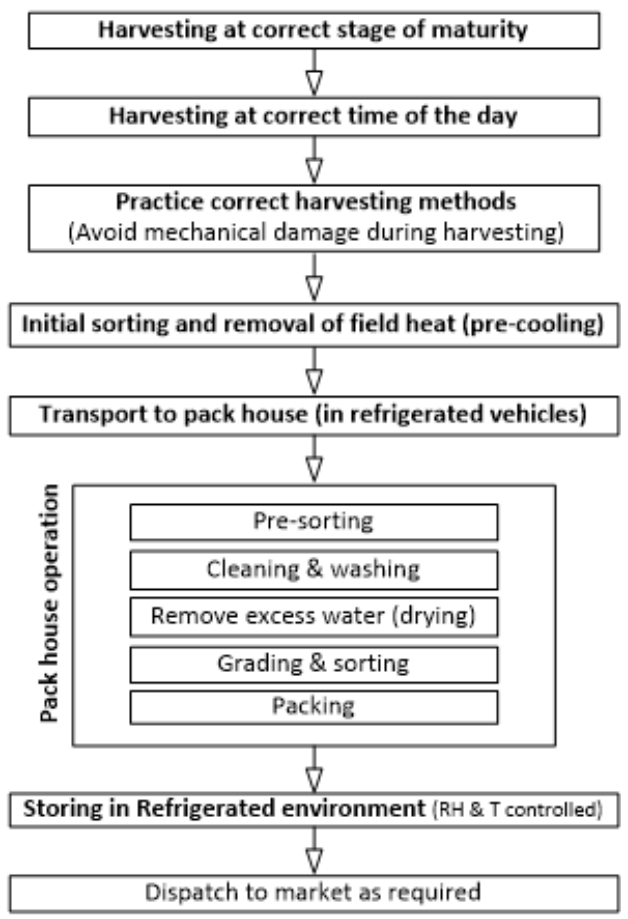

Figure 3 Post harvest handling and cold chain practices (based on ${ }^{3,27}$ ).

\section{Harvesting at correct maturity}

Maturity is the most important factor that determines post-harvest shelf-life and final quality of fresh produce. Generally, maturity level of fruits and vegetables can be identified using maturity indices, and could be detected using physiochemical and morphological characteristics such as chronological age (elapsed days from bloom to harvest), size, shape, firmness, weight, colour, $\mathrm{pH}$, total soluble solids (TSS) and fiber content. ${ }^{17}$ Maturity is the stage of development at which the produce has completed its natural growth and is ready for harvesting. It is that stage of development, which ensures proper ripening. The horticultural (commercial) maturation, however, is related to utilization purposes. For instance, tomato is regarded as mature for fresh market consumption when they are "mature green" in the USA, but in Israel tomato must be at least pink in order to be considered mature for harvest. For the canning industry, tomato is mature only when it is dark red, as the red color is a most important feature of the product. Maturity definition also depends on the part of the plant, which is being consumed. ${ }^{18}$

Because of the great differences between fresh produce, development of specific indices of maturity for each commodity is required. All fruits, with a few exceptions (such as pears, avocados, and bananas), reach their best eating quality when allowed to ripen on the plant. However, some fruits are usually picked mature but unripen so that they can withstand postharvest handling system when shipped long-distance. Most of the currently used maturity indices are based on a compromise between those indices that would ensure the best eating quality to the consumer and those that provide the required level of flexibility in post-harvest handling. ${ }^{16}$

Immature, improperly ripen fruits are more likely to subject to shriveling, inferior flavor quality etc. Over-ripen fruits become softer, and more likely to be subjected to mechanical damage. Fruits picked either too early or too late in their season \& maturity are more susceptible to postharvest physiological disorders than fruits picked at the proper maturity. For example, immature lime fruits are highly prone to be shriveled, mechanically damaged, under nourished and are poor in quality. On the other hand, over-mature lime fruits easily become soft, mealy, lose desirable color and more often have insipid flavor during ambient storage. Therefore, fruits and vegetables harvesting need to consider correct maturity based on subsequent post-harvest process and transport requirement. ${ }^{15,19}$

Fruits can be divided into two groups based on their ripening behavior upon harvesting. Those not able to continue proper ripening process once removed from the plant (such as cherry, citrus fruits, grape, pineapple and pomegranate), and those able to continue ripening process off the plant (eg. apple, apricot, avocado, banana, guava). First group produces very small quantities of ethylene and do not respond to ethylene treatment except in terms of de-greening (removal of chlorophyll); these should be picked when fully-ripen to ensure good flavor quality. Latter group produce larger quantities of ethylene in association with their ripening, and exposure to ethylene will result in faster and more uniform ripening, most vegetables too belonged to this group. ${ }^{3,16,20,21}$

\section{Handling \& transportation}

Careless, non-scientific harvesting and handling practices are major contributing factors of postharvest losses in fruits and vegetables industry in Sri Lanka. Harvesting at maturity that strike a balance between post-harvest processing \& transportation requirements, and a desired level of ripened characteristics is very important. ${ }^{21,22}$ In most developing countries, the production sites for many horticultural and small-scale agricultural producers are far from the marketing centers and in areas difficult to access. Such conditions add factors such as additional time of transit, exposure to physical and mechanical injuries and exposure to solar radiation and extreme weather (such as rain), all of which contribute to increase the degree of losses. Under the conventional system of transportation and transit handlings, fruit and vegetables are packed in gunny bags and transported in ordinary lorries. The charge levied for the lorry based is determined by the number of gunny bags transported and hence, 
the system automatically encourages overloading, overstaying etc to accommodate maximum pay-load per lorry. Use of closed vehicle and tight packing prevent proper ventilation during transportation is another seriously contributing factor. Poor and unsuitable mode of transportation and packaging are major causes for the higher wastage reported in Sri Lanka's fresh fruit and vegetable marketing system. This is the worst recipe for increasing postharvest losses. ${ }^{6,10,23}$

To face the above challenge, some of the established supermarket chains have developed their own appropriate practices, such as of using refrigerated trucks and plastic crates-based packing in the post-harvest operations. Such approaches have reportedly reduced wastage drastically., 90 The improved transport system adopted by the supermarkets are reported incur additional cost, however, the cost disadvantage is more than compensated by higher overall prices resulting from improved quality. Yet, both the initial investment and the operation costs of this supermarket level operations are beyond reach of average small-scale local producers. Even though handlers from developing countries may not have the capacity to use refrigerated trucks, educating them on the consequences of losses in economic terms would certainly have positive impact. ${ }^{24,25}$

\section{Sorting and grading}

The most important processes in packaging and marketing of fruit and vegetables is sorting and grading. ${ }^{26}$ Sorting is the removal of damaged fruits, due to being rotten or subjected to diseases, from the healthy products. ${ }^{27}$ Grading is the process of categorizing on the basis of color, size, stage of maturity, or degree of ripening. ${ }^{27}$ The two processes are vital in maintaining postharvest shelf life and quality of harvested products. Sorting limits the spread of infectious microorganisms from bad fruits to other healthy fruits during storage of products. Grading helps handlers to categories fruits and vegetables in a given common parameter which enables easy handling. For instance, grading on the basis of cooler or maturity stage help eliminate overripe fruits, which easily produce ethylene to hasten the ripening process in the whole batch. ${ }^{28}$

Further, sorting and grading are not done effectively due to lack of suitable storage facilities in the downstream of the chain. Lack of knowledge on temperature requirements, effect of cold chain practices on reducing losses \& ethylene sensitivities of different commodities for mixed loading aggravate the situation play a serious negative role. Lack of national standards, poor enforcement of standards, skill, awareness/ financial resources for grading products etc also contribute to present higher degree of post-harvest losses. ${ }^{29,30}$

Grading is a critically important process that produce an aspect of quality, which is often judged on the basics of uniformity, and it presents a standard for product handling (i.e. unitization) and marketing. Produces are generally graded based on size, weight, colure defects or composition, and/or a combination of these features. A typical size grader for fruit separates produce using diverging conveyor belt, which allow smaller fruits to drop between them first. ${ }^{28}$ Computerizing weight graders can operate on the basis of tipping buckets, which drop to release the pre weight items at a particular position. Video image capture and analysis could also be used for size grading, as well as for color grading and external defect grading. ${ }^{31,32}$

\section{Removal of field heat (pre-cooling)}

Many biological researches have demonstrated the importance of rapid cooling of perishable in extending postharvest life of fresh produce. Lowering internal commodity temperature just after harvesting is critical in extending postharvest life.,33 To achieve sufficiently rapid and efficient decrease in temperature of produce, use of fast cooling systems is particularly important. Use of systems utilizing cool water i.e. hydro-cooling, is a method allowing high heat transfer rates, which could result in three times shorter cooling times in comparison with forced air cooling, or ten times, when produces are placed in conventional or storage room..$^{34,35}$

For most fresh horticulture commodities, one-hour time loss at the field temperature of $30^{\circ} \mathrm{C}$ between harvest and pre-cooling can reduce quality as much as $20 \mathrm{hrs}$ in storage under proper conditions. ${ }^{35,36}$ Delay in pre-cooling results in loss of moisture from the produce causes weight loss and combined with active micro-biological organisms result in deterioration of quality and value loss. The design of the multi-commodity cold store facility and method of pre-cooling depends on various factors such as nature of the produce, category and produce type which determines the period of storage for example short term storage (generally refer to as 7 to 10 days storage) or long/medium term storage. Handling, stacking and storage methods, packaging, frequency of entry and exists to cold storage are also key deciding factors. ${ }^{35,37}$

Fruits and vegetables require on-farm pre-cooling if transport time to reach cold storage is more than few hours. It is desirable that fresh produce like grapes, mandarins, berries, cherries, leeches, melons, stone fruits, sapotas, okra, tomatoes, capsicum, chilli peppers, brinjal, cucumbers, green beans, peas, spinach etc are cooled as rapidly as possible. Less perishable fruits \& vegetables such as mangoes, papaya, guava, green bananas, pomegranates, radish, cabbage, cauliflower and carrot can be transported from the field and pre-cooled at the cold storage facility. ${ }^{37}$

Pre-cooling requirements vary across produces, and also based on method of cooling; room cool, hydro cool, forced air cooling, evaporative forced air cooling and ice packaging. However, forced air cooling within 4-6 hours is adoptable to a wider range of commodities than any other pre-cooling method and may suffice for most of the produce and therefore, it is widely adopted for recommending general technical standards for pre-cooling system. ${ }^{37,38}$

\section{Storage under correct conditions}

This is the most important post-harvest practices of the fruits and vegetable to reduce losses. Cold storages are mainly built to control the rate of transpiration, respiration, microorganism growth and to preserve the fruits and vegetables in most useable form for the consumer. The cold storages slow down the biological activities of the fresh commodities while avoiding the chilling injury and show the microorganism growth. Further, this reduces transpiration losses to avoid various undesirable processes including sprouting, elongation, rotting, greening and toughening of certain fruits and vegetables. ${ }^{39}$

Several factors contribute to the success of fruit and vegetable storage including temperature, humidity, atmospheric composition, air movement and light. The cold storage temperature should be maintained at the desired level for the fruits and vegetables to be stored. The temperature above the optimum will reduce the storage life and the lower temperature may cause chilling injuries. The relative humidity for freshest fruits and vegetables need to be maintained between $90-95 \% .{ }^{39}$ Lower humidity than the desired level of the respective fresh commodity results in moisture loss from the produce. With high relative humidity extra care should be taken to prevent the microorganism growth in the surface. The recommended temperature, relative humidity and storage life (under the temperature and humidity conditions) for various fruits and vegetables grown in tropical countries are given in table 1. 
Table I Recommended storage conditions and durations for crops of tropical countries ${ }^{32}$

\begin{tabular}{|c|c|c|c|}
\hline Crop & Temperature $\left({ }^{\circ} \mathrm{C}\right)$ & Relative humidity (\%) & Storage life (days) \\
\hline Avocado & $3-13$ & $85-90$ & $14-56$ \\
\hline Banana - Plantain & $13-15$ & $90-95$ & $7-28$ \\
\hline Beet (topped) & 0 & $98-100$ & $120-180$ \\
\hline Chinese cabbage & 0 & $95-100$ & $60-90$ \\
\hline Eggplant & $8-12$ & $90-95$ & 7 \\
\hline Ginger & 13 & 65 & 180 \\
\hline Guava & $5-10$ & 90 & $|4-2|$ \\
\hline Leek & 0 & $95-100$ & $60-90$ \\
\hline Lemon & $10-13$ & $85-90$ & $30-180$ \\
\hline Lime & $9-10$ & $85-90$ & $42-56$ \\
\hline Mango & 13 & $90-95$ & $|4-2|$ \\
\hline Melon & $7-10$ & $90-95$ & $|2-2|$ \\
\hline Okra & $7-10$ & $90-95$ & $7-10$ \\
\hline Onions (dry) & $20-25$ & $65-70$ & $30-240$ \\
\hline Orange & $0-9$ & $85-90$ & $56-84$ \\
\hline Papaya & $7-13$ & $85-90$ & $7-21$ \\
\hline Cucumber & $5-10$ & 95 & 28 \\
\hline Bell pepper & $7-13$ & $90-95$ & $|4-2|$ \\
\hline Pineapple & $7-13$ & $85-90$ & $14-28$ \\
\hline Potato (early) & $7-13$ & $90-95$ & $10-14$ \\
\hline Radish & 0 & 95 & 21 \\
\hline Spinach & 0 & $95-100$ & $10-14$ \\
\hline Sweet potato & $13-15$ & $85-90$ & $120-210$ \\
\hline Water melon & $10-15$ & 90 & $|4-2|$ \\
\hline Yam & 16 & $70-80$ & $60-210$ \\
\hline
\end{tabular}

The atmospheric composition or the gases inside the cold storage affect the storage life of the commodities. The atmospheric composition of the storage room is controlled by adding the favorable gases such as carbon dioxide or removing the undesirable gases using chemical or physical methods. ${ }^{25}$ The ventilation system is an essential part of the cold storage. Sufficient air movement should be incorporated to remove the respiration heat. Since the room is exposed to a uniform air flow, free air flow should be ensured through proper stacking of fresh commodities and placement of blowers or ducts. ${ }^{35,39}$ In forced air cooling, the refrigerated air is forced through the fruits and vegetables packed in containers. Several studies aiming to identifying the suitability of using forced air cooling for specific fruits and vegetables and evaluation of the current systems were also available in literature ${ }^{40-42}$ Hydro-cooling is achieved by immersion or sending through a chilled water shower and the water should be chlorinated (150-200ppm) to prevent pathogens accumulation. However, this cannot be used for the commodities that do not tolerate water infiltration, wetting and chlorine. Many pervious researchers have studied the effect of hydro-cooling properties of the stored fruits and vegetables. ${ }^{38,43-47}$

Evaporative cooling is a cost effective method for storing fresh commodities in a hot and dry climate. The evaporative cooling effect increases with the wet bulb to dry bulb temperature difference. This method is most suitable for the rural communities in hot and dry climate due to the lower initial and operation. ${ }^{48}$ Vacuum cooling is used in many food storage applications including beverages and meat products due to its rapid cooling ability. The comparison of product effects and costs for the cooling methods discussed above is shown in Table 2 and the classification of the crops grown in tropical countries according to the cooling method is given in Table $3 .{ }^{49-51}$ 
Table 2 Comparison of cooling methods of produces ${ }^{61,62}$

\begin{tabular}{lllllll}
\hline Product effect & Forced-air & Hydro & Vacuum & Water spray & Ice & Room \\
\hline Typical cooling time (hr) & $1.0-10.0$ & $0.1-1.0$ & $0.3-2.0$ & $0.3-2.0$ & $0.1-0.3$ & $20-100$ \\
Water contact with product & $0.1-2.0$ & $0-0.5$ & $2.0-4.0$ & no data & no data & $0.1-2.0$ \\
Potential for decay contamination & no & yes & no & yes & yes & no \\
Water resistant packaging needed & no & yes & no & yes & yes & no \\
\hline
\end{tabular}

Table 3 Classification of fruits and vegetables based on cooling method ${ }^{56}$

\begin{tabular}{llll}
\hline Room cooling & Forced air cooling & Hydro cooling & Vacuum cooling \\
\hline Banana & Avocado & Cucumber & Cabbage \\
Beet & Banana & Eggplant & Leek \\
Ginger & Cucumber & Leek & Spinach \\
Lime & Eggplant & Orange & Lima bean \\
Lemon & Ginger & Potato & \\
Melons & Guava & Radish & \\
Onion & Mango & Spinach & \\
Orange & Melons & Beet & \\
Cucumber & Okra & Cassava & \\
Pineapple & Orange & Cabbage & \\
Potato & Papaya & Lima bean & \\
Pumpkin & Pineapple & & \\
Radish & Cassava & & \\
Sweet potato & Passion fruit & & \\
Watermelon & Pumpkin & & \\
\hline
\end{tabular}

\section{Concluding remarks}

The process of handling fruit and vegetables from producer to consumer was investigated based on published research as applicable to Sri Lanka, with an objective of identifying factors that contribute to present day significant post-harvest losses of the produces. The study broadly identified several contributing factors to the recorded significant post-harvest losses, as well as gaps in present operation that limits the potential of local farmers getting the due economic benefits, and also reaching foreign markets in possible cases. In rural farming, the issues of lack of awareness of market dynamics, lack of knowledge on good practices and economically beneficial procedures such as sorting, grading, precooling, not having access to a wellcoordinated transport system that reduces processing and waiting time of produce etc. are major issues that contribute to substantial fraction of the overall postharvest losses.

Among other contributing factors, not having a well-coordinated, well-practiced integration of cold chain and appropriate cold chain elements with the prost harvest process of fresh produce appears to contribute significantly to the recorded postharvest losses. Institutional and government support in coordinating the food chain practices concerning fruits and vegetables with properly integrated cold chain practices appear to be not well established. In this regard, in addition to providing cold chain elements such as suitably designed and operated environment-controlled storages and other hardware (temperature and RH mainly), temperature controlled long distance scientifically stacked transportation etc. implementation of regulations and policies to make sure the system will sustain is very important. ${ }^{52-62}$

Further, the need for coordinated streamlined operation of economic centers that handle the produce in bulk was well noted among the relevant research, indicating the necessity for strengthening the relevant policy framework. In the market chain, unavailability of a recognized pricing structure that give priority to quality of harvest in some ways appear to be a discouraging fact at grass root level to minimize waste of produce. In addition, implementing post-harvest operations such as sorting, grading and pre-cooling at satisfactory level, improving storage facilities to maintain the basics of reducing handling waste seems promising steps in improving status quo of the present-day post-harvest process. In this regard a firm government policy and regulatory enforcement in post-harvest handling, storage and transportation aspects will certainly make sure the governments subsidies disbursed at grassroots level for farming are better utilized.

\section{Funding}

None.

\section{Acknowledgments}

None.

\section{Conflicts of interest}

The authors declare that there was no conflict of interest. 


\section{References}

1. https://www.adb.org/sites/default/files/project-documents /49273/49273-001-tacr-en_4.pdf

2. Annual report, Central bank of Sri Lanka. 2018.

3. Kitinoja L. Use of cold chains for reducing food losses in developing countries, PEF White Paper No. 13-03, The Postharvest Education Foundation, Oregon, USA. 2013:1-16.

4. Gunathilake DMCC, Tiwari AK. Evaluation of Efficacy of Washing Treatment for Extending the Post-Harvest Life of Tomato (Solanum lycopersicum L). Int J Curr Microbiol App Sci. 2017;6(11):1999-2004.

5. Kitinoja L. Returnable Plastic Crate (RPC) systems can reduce postharvest losses and improve earnings for fresh produce operations, PEF White Paper No. 13-01, The Postharvest Education Foundation, Oregon, USA. 2013. 1-30.

6. Kitinoja LS, Saran SKR, Kader AA. Postharvest technology for developing countries: challenges and opportunities in research, outreach and advocacy. J Sci Food Agric. 2011;91(4):597-603.

7. Leyte JC, Forney CF. Optimizing flat design for forced-air cooling of blueberries packaged in plastic clamshells. Journal of Hort Technology. 1999;9(2):202-205.

8. Agricultural statistic reports of Sri 2019. Department of Census and Statistics, Sri Lanka.

9. Fernando MD. Country paper - Sri Lanka (2), In: Proceedings of seminar on post-harvest management of fruit and vegetables in the Asia-Pacific region, Asian Productivity Organization (Tokyo) and UN FAO (Rome). 2006

10. Jayathunge KGLR, Wasala WMBC, Rathnayake HMAP, et al. Evaluation of different types of packages for handling and transport of vegetables, technical note, Institute of Post-Harvest Technology, Sri Lanka. 2009.

11. Technical Standards for cold storage. Cold storage of fresh horticulture produce requiring pre-cooling before storage, technical standards number NHB-CS-Type -02-2010, National Horticulture Board, Ministry of Agriculture, Haryana, India. 2010.

12. Dissanayake CAK, Wasala WMCB, Gunawardhane CR, et al.. Introduction of plastic crates to vegetable wholesalers in major economic centers in Sri Lanka: why do people refuse it? In IV International Conference on Postharvest and Quality Management of Horticultural Products of Interest for Tropical Regions. 2017;1278(23):151-156.

13. Win TO, Srilaog V, Kyu KL, et al. Biochemical and physiological chagesuring chlorophyll degradation in lime (Citrus aurantifolia Swingle cv. 'Paan'). Journal of Horticultural Science \& Bio-technology. 2006;81(3):471-477.

14. JAICA. Democratic Socialist Republic of Sri Lanka - Data Collection Survey on Agricultural distribution network and marketing - Final Report. Japan International Cooperation Agency System Science Consultants Inc.

15. Gunathilake DMCC, Tiwari AK, Tharanga Kahandawala KA. Efficacy of washing treatment for extending the post-harvest shelf-life of papaya (Carica papaya). Int J of Chemical Studies. 2018;6(4):229-635.

16. Kader AA. Postharvest Technology of Horticultural Crops. 3rd edn Division of Agriculture and Natural Resources, University of California Davis, CA. Puvlication No.3311. 2002.

17. El-Ramady HR, Domokos-Szabolcsy É, Abdalla NA, et al. Postharvest management of fruits and vegetables storage. Sustainable agriculture reviews. 2015:65-152.

18. Irtwange SV. Maturity, Quality and Marketing of Fruits and Vegetables. International Commission of Agricultural Engineering. 2006;8(7).

19. Saltveit ME. Effect of ethylene on quality of fresh fruits and vegetables. Postharvest Biology and Technology. 1999;15(3):279-292.
20. Perera M, Sarath SKSS, Weerahewa J. Analysis of Vegetable Supply Chains of Supermarkets in Sri Lanka, Sri Lankan Journal of Agricultural Economics. 2004;6(1):67-82.

21. Win TO, Srilaog V, Heyes KKLJ, Kalyanarat S. Effects of different concentrations of 1-MCP on the yellowing of West Indian lime (Citrus aurantifolia, Swingle) fruit. Postharvest Biology and Technology. 2006b;42(1):23-30.

22. Kader AA. Fruit Maturity, Ripening, and Quality Relationships. Acta Horticulture. 1999;485(27):203-208.

23. Rupasena L. Production and marketing of vegetables. 1999.

24. Arah IK, Ahorbo KG, Anku EK, et al. Postharvest Handling Practices and Treatment Methods for Tomato Handlers in Developing Countries. Advances in Agriculture. 2016.

25. Rao CG. Engineering for storage of fruits and vegetables: cold storage, controlled atmosphere storage, modified atmosphere storage. Academic Press. 2015.

26. Arjenaki OO, Moghaddam PA, Motlagh AM. Online tomato sorting based on shape, maturity, size, and surface defects using machine vision. Turkish Journal of Agriculture and Forestry. 2013;37(1):62-68.

27. Technical reports on fruits and vegetables post-harvest technology. Institute of Post-Harvest Technology (IPHT), Anuradhapura, Sri Lanka. 2010 .

28. Martínez-Romero D, Castillo S, Valero D. Forced-air cooling applied before fruit handling to prevent mechanical damage of plums (Prunus salicina Lindl.). Postharvest biology and technology. 2003;28(1):135142.

29. Gunathilake DMC C, Wasala WMCBKB, Palipanea. Design, development and evaluation of a size grading machine for onion. Journal of Procedia Food Science. 2016;6:103-107.

30. Wasala CB, Dissanayake CAK, Dharmasena DAN, et al. Postharvest losses, current issues and demand for postharvest technologies for loss management in the main banana supply chains in Sri Lanka. Journal of Postharvest Technology.2014;2(1):80-87.

31. Clément V, James TSW. Postharvest Technologies for Horticultural Crops California, USA. 2009;2:25-47.

32. FAO agricultural services bulletin no. 151. Manual for the preparation and sale of fruits and vegetables: from field to market, FAO. Food and Agriculture Organization of the United Nations, Rome, Italy. 2004.

33. Thompson JF, Mitchell FG, Rumsey TR, et al. In: Commercial cooling of fruits, vegetables and flowers. University of California, Agriculture and Natural Resources. 2008;21567:61-92.

34. Nkolisa N, Magwaza LS, Workneh TS, et al. Evaluating evaporative cooling system as an energy-free and cost-effective method for postharvest storage of tomatoes (Solanum lycopersicum L.) for smallholder farmers. Scientia Horticulturae. 2018;241:131-143.

35. Thompson JF, Mejia DC, Singh RP. Energy use of commercial forced-air coolers for fruit. Applied Engineering in Agriculture. 2010;26(5):919924.

36. Fraser H, Otten L. Predicting 7/8 Cooling Times for Peaches by Compairing Heat Transfer Modelling and Field Measurement Methods. Sent Joseph. ASAE, Paper 92-6016.1992:10.

37. Teruel B, Kieckbusch T, Cortez L. Cooling parameters for fruits and vegetables of different sizes in a hydrocooling system. In: Sci Agric. 2004;61(6):655-658.

38. Joyce C, Willis O, John K, et al. Combinatorial effects of hydro-cooling, sanitizer application and cold storage in maintaining quality of selected vegetables. Proc. $1^{\text {st }}$ All Africa Post Harvest Congress \& Exhibition, Reducing food losses and waste: sustainable solutions for Africa, University of Nairobi, Nairobi, Kenya. 2017. 
39. Rapusas RS, Rosa SR. Management of reusable plastic crates in fresh produce supply chains, A technical guide, Food and Agriculture Organization of the United Nations Regional Office for Asia and the Pacific Bangkok. 2009.

40. Barbin DF, Neves FLC. Portable forced-air tunnel evaluation for cooling products inside cold storage rooms. International journal of refrigeration. 2012;35(1):202-208.

41. Liang YS, Wongmetha O, Wu PS, et al. Influence of hydro-cooling on browning and quality of litchi cultivar Feizixiao during storage. International Journal of Refrigeration. 2013;36(3):1173-1179.

42. Mitchell FG. The Need for Cooling. In Kader AA. (Ed.), Postharves Technology of Horticultural Crops, Division of Agriculture and natural Resources, University of California. 1992;53-56.

43. Acedo A, Thanh CD, Van LTS, et al. August. Tomato precooling using simple hydrocooler and fruit quality changes during ambient and cold storage. In Asia Pacific Symposium on Assuring Quality and Safety of Agri-Foods. 2008;837:135-140.

44. França C, Santos M, Ribeiro W, et al. Shelf life of iceberg lettuce affected by hydro cooling and temperature of storage. Advances in Horticultural Science. 2018;32(3):319-324.

45. Hevia F, Wilckens R, Lanuza $P$, et al. Influence of hydrocooling and fruit color on the behavior of Bing sweet cherries after refrigerated storage. In III International Cherry Symposium. 1997;468:731-736.

46. Londhe D, Nalawade S, Pawar G, et al. A review of different methods of grading for fruits and vegetables, The CIGR e-journal. 2013;15(3):217230 .

47. UC Davis Post-harvest report harvest reports Ucce.ucdavis.edu. 2020.

48. Gunathilake DMCC, Fernando MD, Palipane KB. Design and Development of a 1000kg Capacity Wet Evaporative Cooing Chamber to Preserve Fruits and Vegetables, Technical note, Institute of Post-Harvest Technology, Sri Lanka. 2004.

49. Anyanwu EE. Design and measured performance of a porous evaporative cooler for preservation of fruits and vegetables. Energy Convers Manage. 2004;45(13-14):2187-2195.

50. Gulandaz MA, Sayed A, Nur-A-Alam M, et al. Modeling of Potato Shelf Life on Evaporative Cooling Storage. Journal of Life Sciences Research. 2017;4(1):5-13.
51. Panghal A, Yadav DN, Khatkar BS, et al. Post-harvest malpractices in fresh fruits and vegetables: food safety and health issues in India. Nutrition \& Food Science. 2018;48(4):561-578.

52. Agro- climatic regions of Sri Lanka. Department of Agriculture, Sri Lanka. 2016.

53. Basediya LA, Samuel DVK, Beera V. Evaporative cooling system for storage of fruits and vegetables-a review. J Food Sci Technol. 2013;50(3):429-442.

54. Dadhich SM, Dadhich H, Verma R. Comparative study on storage of fruits and vegetables in evaporative cool chamber and in ambient. International Journal of Food Engineering. 2008;4(1).

55. Edgar LV, Floyd MW, Joseph MK. Use of External Indicators to Predict Maturity of Mini-watermelon Fruit. Journal of Hort-Science. 2010;45(7):1034-1037.

56. FAO report. Alternative supply chain management practices and the performance of marketing channels in fresh fruit and vegetable marketing in Sri Lanka. 2020: 41-131.

57. FAO report. Fruit and Vegetables processing, FAO Agricultural Service Bulletin 119, Rome, Italy. 1995.

58. Kaewsuksaeng S, Tatmala N, Srilaong V, et al. Postharvest heat treatment delays chlorophyll degradation and maintains quality in Thai lime (Citrus aurantifolia Swingle cv. Paan) fruit. Postharvest Biology and Technology. 2015;100:1-7.

59. Samaradiwakara SD, Champa WAH, Eeswara JP. Harvest Maturity Affects Postharvest Quality of Lime Fruits (Citrus aurantifolia Swingle). Tropical Agricultural Research. 2019;30(4):125-131.

60. Toivonen PM. The effects of storage temperature, storage duration, hydrocooling, and micro-perforated wrap on shelf life of broccoli (Brassica oleracea L., Italica Group). Postharvest Biology and Technology. 1997;10(1):59-65.

61. Zhu Z, Geng Y, Sun DW. Effects of operation processes and conditions on enhancing performances of vacuum cooling of foods: A review. Trends in food science \& technology. 2019;85:67-77.

62. Zhu Z, Wu $\mathrm{X}$, Geng $\mathrm{Y}$, et al. Effects of modified atmosphere vacuum cooling (MAVC) on the quality of three different leafy cabbages. LWT. 2018;94:190-197. 